\title{
Making diffusion and adoption issues part of the design options and solution strategies for the international office of the future
}

\author{
Jan Pries-Heje, Copenhagen Business School, Denmark, Chair \\ Priscilla Fowler, Software Engineering Institute, Carnegie-Mellon \\ University, USA \\ Karlheinz Kautz, Norwegian Computing Center, Norway \\ Gonzalo Leon Serrano, Universidad Politecnica de Madrid, Spain
}

\section{INTRODUCTION}

In the process of developing the Global multi-site conference for 1997 and especially in the time after that conference the issues of diffusion and adoption of IT become very important. The aim of this panel is threefold. First it will raise the diffusion and adoption issues. Second, it will overview the most important and salient diffusion and adoption issues from five different but complementary perspectives. Third it will enable discussion of these issues in relation to the International Office of the Future.

The panel members are active members of the new IFIP Working Group 8.6 on Diffusion and Transfer of Information Technology. The format of the panel will allow each panel member to briefly raise and address one of five key technology transfer and diffusion questions leading to open discussion from the floor. Fowler)

Global Multi-Site Conference: Simulation Of What?

The futurist in me is enchanted with the idea of all that technology in the third conference of this exciting three-conference series. What an idea! An around-the-world conference "simulating the office environment of a globally distributed real or virtual organization." The pragmatist, veteran of many a failed technology adoption and implementation plan, is sceptical. All that technology (and all those technologists) simulating away! Where are the rest of us, with our human and organizational issues, and our desire to get "real" work done?

Technologies mature in context - in use. The best technologies have mechanisms for adaptation built right into them. For example, most organizations have used templates for word processors for 
years to encapsulate corporate forms, letterhead, etc. Most large-scale commercial suppliers of software routinely create language - or culture-specific versions of their products. What is the equivalent for the technological components of the office of the future? How will these technologies get adopted, adapted, and integrated? Will their use be codified by domain: medicine, aerospace, manufacturing?

The challenge of conference 3 will be to demonstrate, not generic technology like so many innovators and early adopters, but specific, adapted technologies for a typical modern business domain. When one can ring up a local supplier, specify a new business arrangement (eg. a virtual organization to install a new oil refinery) and readily get an environment configured to their own business requirements, then the international office of the future will have arrived.

\section{CURRENT WISDOM ON DIFFUSION AND ADOPTION (Jan Pries-Heje) How do you bring research on the International Office of the Future into the real office?}

There is no easy answer to that question but there is a lot current wisdom focusing on different parts of adoption and diffusion. One of the well known research schools is Diffusion of Innovation Theory. This theory can provide pragmatic guidance to the people facing the task of implementing the Office of the Future. Other theories focus on the role of learning, culture, context and human networking. All these theories can provide valuable contributions to the successful planning and diffusion of new IT within the future office. How and why this can be done will be explained.

\section{THE DEVELOPER'S PERSPECTIVE (Karlheinz Kautz) What will developers have to take into account when developing the International Office of the Future?}

The international office of the future has become more than a just a vision. The technology, at least in part, exists, but is not yet used in many commercial organisations. So what are the challenges for system developers in this field? From a technical point of view there still is some work to do. The necessary technical infrastructure is not in place everywhere. Neither are true distributed architectures which allow efficient use of the technical resources without the need to have all software to share applications at all physical locations. Cross platform connectivity has not been achieved either. For example there is still work to do making the UNIX and the PC world communicate with each other. These are technical challenges, but software engineers are already working on them and will come up with solutions. However, the real moment of truth will come when the office technology meets the users and the basic technology so far has been developed mainly in R\&D departments with a long, long distance between the developers and the users. As one of my colleagues expressed it: "It is hard work to sell the idea of distributed cooperation to organisations to help them solve problems which they might not have discovered yet". So the distance to the users has to be diminished. Development projects which have not yet involved users should plan for and conduct structured, not incidental evaluation of their prototypes.

A general requirement for the technology going into the office of the future is that the communication support should be as invisible as possible. The users should still be able to concentrate on their work tasks and should not be distracted by the technology. But what this really 
means for all the different kinds of users can only be learned by involving them. This is however not that easy with users distributed over the whole world representing different cultures. And if user involvement is not possible system development should as an integral part include an introduction strategy. This also is part of the work of developers.

\section{$5 \quad$ MANAGERIAL ISSUES (Jan Pries-Heje)}

What steps should managers take to successfully integrate the Office of the Future into their organizations?

Business trends in the last years of the Twentieth Century emphasise the design and implementation of efficient and effective business processes, the establishment of core competencies, the divestiture of non-core activities, and the development of business relationships across organisational and geographic boundaries. The result is a leaner, more focused organisation with an external network of cooperative business relationships. They therefore require greater communication and coordination rather than direct, internal control. The office of the future, conceptualised as a means of coordinating across space and time, appears to address this need. It might be thought therefore that business managers would be keen to move to new forms of office.

The office of the future, however, is not a primary component of the value chain. It is an infrastructural concept and its constituent technologies are likewise infrastructural. Managers have too often burnt their fingers on IT infrastructural developments decoupled from concrete business benefits. Unless the strategic value and the near term benefits are evident and achievable managers are unlikely to be keen to invest heavily in the office of the future.

Research into the dynamics of IT-based organisational transformations has yielded some insights into the different paths which companies might take so as to obtain business value through exploiting the opportunities presented by the office of the future. The range of such paths is outlined. Of particular interest is the extent to which critical mass theory may apply to the office of the future and hence point to constraints on the range of successful paths available to managers.

\section{ORGANISING THE ADOPTION PROCESS (Gonzalo Leon Serrano) How can you do it?}

The introduction of new IT in the office not only affects the way that the work is done; it also introduces a new dimension of the workplace and raises questions about the external recognition of new jobs. This section of the panel will analyze the way that the organization understands the innovation process and facilitates or complicates the introduction of a new technology. More specifically, we will present two conceptual tools for organizing the adoption process inside the company:

1. Circles of involvement: how to involve the company as a whole in the process to be sure that the new technology penetrates all levels of responsibility.

2. Adoption profiles: how to anticipate problems the company might encounter during the adoption process. 